\title{
Individuality and Aggregativity
}

\author{
Stéphane Chauvier*
}

\begin{abstract}
Why is there a specific problem with biological individuality? Because the living realm contains a wide range of exotic particular concrete entities that do not easily match our ordinary concept of an individual. Slime moulds, dandelions, siphonophores are among the Odd Entities that excite the ontological zeal of the philosophers of biology. Most of these philosophers, however, seem to believe that these Odd Cases oblige us to refine or revise our common concept of an individual. They think, explicitly or tacitly, that to be a living, evolutionary entity is to be a living individual. In this paper, we explore an alternative proposal: the variety and oddity of the forms of the living realm might be ontologically regimented through an increase in the categorial complexity of the living realm, by admitting, beside living individuals, living non-individuals or by acknowledging, more generally, that the evolutionary development of the living forms is not necessarily a process of building individuals, that life is not necessarily individuals-oriented. We claim that, from an ontological point of view, the spectacle of the living realm obliges us to take aggregativity seriously.
\end{abstract}

$$
\begin{gathered}
\text { Keywords } \\
\text { aggregates } \bullet \text { conglomerates } \bullet \text { individuals } \bullet \text { formal and material ontology } \\
\text { metaphysics of science } \bullet \text { philosophy of biology }
\end{gathered}
$$

Part of a special issue, Ontologies of Living Beings, guest-edited by A. M. Ferner and Thomas Pradeu

Editorial introduction: In this paper, Stéphane Chauvier makes a metaphysical objection to one of the main debates in philosophy of biology, namely the debate over the notion of biological individuality. Many philosophers of biology have argued that our traditional concept of an individual is unable to account for the incredible diversity of living things. Many colonial organisms, fungi, protists, symbiotic associations, etc. display features that seem to violate several 'classic' criteria of individuality, such as boundedness or autonomy.

*Professeur à l'Université Paris-Sorbonne, Directeur de l'UFR de philosophie, 1 rue Victor Cousin, F-75230 Paris cedex 5, France, stephane.chauvier@paris-sorbonne.fr

Received 22 July 2016; Accepted 28 January 2017 doi:10.3998/ptb.6959004.0009.011 
But, Chauvier points out, there are many ways to exist in the living world without necessarily existing as an individual. In other words, philosophers of biology might well have mistakenly conflated existence and individuality.

One chief advantage of Chauvier's proposal is that it brings together major debates in metaphysics (e.g. the reality of aggregates, and part-whole relationships) and philosophy of biology (e.g. major transitions in evolution). Yet further investigation might better connect the two fields. For example, biologists and philosophers of biology have long taken into account the existence of aggregates, but their question is: under which conditions does an aggregate become an individual? It is not clear that the criteria they use to understand this transition will be similar or the same as those suggested by Chauvier here. In most cases, they use criteria grounded in biological domains or practices-such as fitness-based or histocompatibility-based considerations. It remains a key challenge to determine how these biological criteria are related to metaphysical criteria such as those examined by Chauvier.

Another question pertains more directly to ontology per se. As explained in the general introduction to this special issue, participants in the debates about the ontology of living beings must specify how they understand the word 'ontology.' Chauvier concludes his contribution with these words: 'an individual-oriented ontology must go hand in hand with an ontology of aggregativity.' Does this mean that we have two distinct series of existing entities? If so, how do they interact? Do we, alternatively, have a single list of existing entities, but a wide variety of such entities? If the latter, then do these entities exist in the same sense and to the same degree (does a cluster of cells or a siphonophore exist in the same way as a cat)? Since, like Leibniz, Chauvier seems to associate individuality with a specific mode of reality - he writes, "We will use 'entity' to denote a phenomenally salient concrete unity, that can turn out to be a real unitary being (an individual) or a stabilized aggregate of real unitary beings (individuals)" - the ontologies of individuals and of aggregates might perhaps end up diverging in their degree of existence or substantiality.

$-\mathrm{AF} / \mathrm{TP}$

When metaphysical problems are found to be intractable it is wise to adopt a critical attitude towards them. One should assess whether the difficulties encountered stem from the problems themselves, rather than a biased way of addressing them, from the presence of some unnoticed prejudice that hinders the formulation of a simple solution.

It is this critical attitude that we would like to adopt in relation to the recalcitrant problem of biological individuality. In our view, the difficulty of producing satisfactory criteria of biological individuality cannot be entirely explained by the ontological bizarreness of living entities. Another explanation registers on a methodological level and is tied to a kind of individualistic prejudice, to the a priori idea that a genuine living entity bas to be an individual.

Starting with a short characterization of the problem, we will argue in favour of a more liberal attitude, that we will label the Reflective Equilibrium Method, which, in our view, is immune to any prejudice concerning the ontological orientation of the natural selection process.

\section{Short Characterization of the Problem of Biological Individuality}

In order to characterize the structure of the problem of biological individuality, it may be helpful to call on the distinction between formal and material ontology, introduced by Husserl in his Logical Investigations (Husserl 1970, III, §11). In Husserl's view, 'formal ontology' is the part of metaphysics that deals with universally or transcendentally applicable ontological concepts, concepts that categorize every kind of being in the various realms of the natural and the social 
world. For Husserl, concepts such as object or part and whole are formal ontological concepts, since we can find objects or wholes in every material field.

By contrast, material ontology deals with concrete categories of beings, such as sounds, feelings, bits of matter, social institutions. The main aim of material ontology is to scrutinize the specific ways these various concrete beings instantiate the formal ontological concepts. How, for instance, is the part/whole relation figured when we consider an aria or a libretto or an institutional entity such as a State?

Following the Husserlian distinction, the problem of biological individuality can be framed as follows. On one hand, we have a 'formal' or 'transcendental' concept of an individual. The concept is one that will be fleshed out in due course, but for now let us say, roughly, that an individual is a particular, bounded, concrete entity, which can be counted. In that general sense, a god, an angel, a star, a cup of tea, a banking crisis can all be viewed as individuals in their own realm. On the other hand, we have a specific material or regional realm, the realm of living entities. And philosophers ask how the 'formal' or 'transcendental' concept of an individual can map onto the diverse multitude of material, biological entities-from genes, to organisms, to species. Which biological things count as individuals? How is the formal individual concept instantiated in the living realm?

But it is quite clear that a material ontology cannot simply consist in the routinized application of a formal concept to a material content. It might be a pleasant game-the game of applying formal concepts to material contents-but it is not a serious cognitive matter. If a material ontology in general and, in our case, an ontology of living beings or bio-ontology is of scientific interest, it is because the living realm, as described by contemporary biological sciences, is comprised of a wide range of particular concrete living entities which don't easily match our general or 'formal' concept of an individual. The literature on biological individuality is full of Odd Cases, which disturb the use of our common concept of an individual and render the question of biological individuality much more puzzling.

In our view, however, the existence of these Odd Cases (detailed below), does not, in and of itself, sufficiently explain the persistent debates concerning biological individuality. We think the debate persists because there are two divergent paths to overcoming the mismatch between the 'formal' and the 'material,' which correspond to two particular conceptions of the aims of applicative metaphysics.

The Scientific Metaphysics View (as we will call it) sees the Odd Cases as obliging us to revise or refine our concept of an individual. More generally, proponents 1 of the Scientific Metaphysics View hold that the disconnect between 'material' and 'formal' legislates a revision to the latter. The so-called formal ontology is mainly an off-ground speculation that has its roots in the grammar of our natural language and in the habits of our perception; but-they continue-if we want to know what there is, we shouldn't investigate the form of our thought or of perception but the discoveries of science. For proponents of the Scientific Metaphysics View, we must therefore find a definition of biological individuality that embraces the Odd Cases as much as the ordinary cases; and the problem arises because the Odd Cases are often very odd, so the working out of a consistent and satisfying concept of biological individuality faces persistent difficulties.

However, there are other views on offer. Contrary to the Scientific Metaphysics View, the Reflective Equilibrium View (as we will call it) does not necessarily call for a revision or excision of the 'old-fashioned,' 'formal' concept of the individual, because we can be content with this

${ }^{1} \mathrm{Cf}$. for instance Ladyman \& Ross 2007. We will see in conclusion that the problem with this view is not its scientific orientation, but its individuals-oriented view of the evolution of life forms. 
formal concept so long as it appears to be consistent and applicable in the various material realms. The solution could either come in the form of a revision of our formal concept, or the introduction of another ontological category, the choice between revision and increased categorial complexity being a matter of what we propose to call a 'reflective equilibrium' (to redeploy Rawls's term from Rawls 1999, 18-19).

Our point is that the problem of biological individuality is not necessarily solved through the specification of a 'new' individual concept, which can cover the variety of forms found in the living realm and mirror the world as described by the biological sciences. The problem of biological individuality may be better solved through an increase in categorial complexity of the living realm, by admitting, beside living individuals, living non-individuals or by admitting, more generally, that the historical development of the living forms is not necessarily a process of individuals building, that life is not necessarily individuals-oriented.

\section{Two Sources of the Problem of Biological Individuality}

The living realm hosts concrete living entities ${ }^{\natural}$ whose behaviour, ontologically speaking, fails to match easily with our formal concept of an individual. The literature on biological individuality is full of Odd Cases that obviously disturb the use of our individual concept. However we propose to make a distinction between two very different sources of disturbance in the application of the concept to the living realm.

One source of disturbance is tied with the role of Natural Selection Theory in the economy of the biological sciences. A number of authors believe that the fundamental entities of the living realm are those to which natural selection applies, the so-called units of selection. This means that we can use natural selection theory as a tracker of biological fundamentality, i.e. which entities are fundamental, explanatorily (and perhaps ontologically), when explaining biological phenomena-from microscopic interactions, to macroscopic fluctuations. What seems to us somewhat puzzling is that the problem of biological fundamentality is equated with the problem of biological individuality. The prevalent assumption seems to be that if something is a unit of selection or a 'fundamental' biological entity, it must therefore be an individual. Accordingly, genes, populations, species are mooted as individuals, because they are all possible units of selection (Hull 1978).

Unfortunately, we fail to see a compelling reason for such a connection. We do not see, particularly, why the fact that a population, a group or a species being a unit of selection would imply that it must be an individual. The unity of a unit of selection need not be of the kind that is typical of an individual. There are clearly various forms and grades of unity. As we will see below, a great number of natural or social aggregates have an internal unity; this does not imply they are individuals. So it seems to us that the defenders of the Unity of Selection View of Biological Individuality have to establish independently that nothing can be a unit of selection if it is not a genuine individual - and we are not sure that there is a proof of that general thesis.

Let us leave this concern to one side. Another source of the problem of biological individuality - much more resistant or serious in our view-is the fact that life contains living entities for which we may hesitate between two interpretations: treating the entity as a concrete aggregate of smaller individuals or treating the living entity as what we will label a super-individual, namely a real individual, but which is composed of actual or of potential individuals.

\footnotetext{
${ }^{2}$ We will use 'entity' to denote a phenomenally salient concrete unity, that can turn out to be a real unitary being (an individual) or a stabilized aggregate of real unitary beings (individuals).
} 
This particular ontological problem is a variant of the general problem of the One and the Many. Much of the time, there is no real difficulty in asserting that a concrete whole is more than a concrete collection of material parts, that it has a proper unity and is a proper subject of actions and passions. But in the living world, we find some more puzzling cases, wherein it genuinely isn't clear whether some thing is an individual (One) or an aggregate (Many).

Every puzzling case we will consider concerns entities that are spatially extended and bounded. We know of no case in which a single living entity is widely scattered with, for instance, a part in Japan and another in Australia. Of course, 'bounded' does not mean that every part is contiguous with some others part, that the entity doesn't contain any holes or internal empty spaces. But there is always a global mass of living matter, a biomass, that has spatial boundaries, even fuzzy boundaries, forming a phenomenally salient concrete unity.

Among these puzzling Odd Cases, which perfuse the literature, we think a distinction can be made:

1. We may have a spatially-extended and bounded living entity that can be seen either as an aggregate of qualitatively identical individuals (Many) or as a large, geneticallyhomogeneous individual (One). For example: slime moulds, a field of dandelions, a coral reef, a forest of quaking aspens (and, more generally, a clonal colony).

Within this class, there is a further distinction to be made: (i) In some cases, the qualitatively identical parts are physically related by various biological appendices, and are vitally connected to one another (e.g. slime moulds, quaking aspens, gigantic fungi). (ii) In other cases, the qualitatively identical parts are spatially separated, but have a common origin: they form a clonal lineage, as though a single individual has duplicated itself, reiterated by each clonal duplicate an indefinite number of times (e.g. dandelions, clonal bacteria colonies).

2. We may also have a spatially-extended and bounded entity that can be seen either as a structured aggregate of heterogeneous living individuals or as a super-individual made up of actual living individuals.

The main instances of this are the colonial siphonophores, including the famous Portuguese man of war, but others include concrete communities of bees, termites, and ants (and, in another register, the pervasive phenomena of symbiosis). Though diverse, from an ontological point of view these instances can be gathered together, for they all disclose the same formal structure: that of the division of a common biological labour between distinct individuals.

Common to (1) and (2) is the fact that we can identify, within the concrete holistic entity, a set of parts that, if encountered in isolation elsewhere, would be viewed as discrete individuals. The main difference between (1) and (2) is that in the first, the individualizable parts form, together, an unstructured agglomerate, while in the second cases, we find a structuration or a functional integration of these individualizable parts.

With these different varieties of Odd Cases in mind, we will try to give an illustration of the Reflective Equilibrium Method mentioned above. Accepting that the task of a 'material ontology' is to arbitrate between ontological revisionism and categorial complexity, our point is that the existence of these Odd Cases - the main root of the problem of biological individualitydoes not necessarily legislate a revision of our formal concept of an individual. Furthermore, we will maintain, attention to these aspects of the living realm obliges us to take aggregativity seriously. 


\section{Individuals, Mixtures, Aggregates and Conglomerates}

\section{(A) Individuals}

Before trying to 'take aggregativity seriously', it is important to take individuality precisely ( ... if, perhaps, a little bit dogmatically $\left.{ }^{3}\right)$. We will sketch the two relevant levels of analysis of the individual concept: the 'formal' and the 'material' (biological).

(1) Let's begin with what we have called the 'formal' concept of an individual. There is, in our view, an important distinction to be made between a logical-cognitive concept of an individual and an ontological one. It is frequently said that an individual is a particular, bounded, concrete entity, which can be counted and re-identified (See for instance Strawson 1959, part 1, passim). This, however, is insufficient when we take the concept of an individual as an ontological concept: something more must be said about its metaphysical character.

There are three further features of the concept of an individual that are worthy of mention:

(i) One basic and traditional feature of ontological individuality, one 'existential moment' of individuality, to use Roman Ingarden's terminology, is ontological separateness. ${ }^{\text {. }}$ An individual must be, to put it in an old-fashioned way, an ens per se and not an ens in alio and per alio. It must have its 'proper being' and not the being of another with which it forms an existential whole This doesn't mean, of course, that an individual cannot be causally related to other things, that it has to be an absolute being. It only means that an individual must be, in a certain sense, independent. For instance, Socrates is an individual, but his nose is not, even if we can treat his nose as a discrete particular, countable and reidentifiable - the reason is that Socrates's nose is dependent, for its existence on Socrates himself: its being is the being of Socrates, while the being of Socrates is his own.5 An individual is then an ens per se, while a non-individual, even a concrete non-individual, is an ens in alio or an ontologically dependent entity.

(ii) Another basic feature of ontological individuality is formal indivisibility. To quote the seventeen-century philosopher Stephanus Chauvinus: 'We call properly individual, not what cannot in any way be divided, but what cannot be divided into several individuals of the same kind as itself or into several individuals specifically similar to him. ${ }^{\prime}$ Here

${ }^{3}$ For a less dogmatic analysis of the formal concept of individual, cf. Chauvier 2016.

${ }^{4}$ Or self-sufficiency (Selbstständigkeit), by contrast with inseparateness or not-self-sufficiency (Unselbstständigkeit). See Ingarden 2013, §14. Self-sufficiency or separateness, in Ingarden's terminology, must not be confused with what he calls existential autonomy. Autonomy is an 'existential moment' of every real beings, by contrast with the 'heteronomy' of intentional beings (such as fictional entities). One can note however that if we set aside Ingarden's theory of intentional being, if we only admit real being, existential autonomy could be use as a synonymous of existential separateness or self-sufficiency, while heteronomy would be another name of not self-sufficiency. We will ourselves speak below of biological autonomy in the separateness sense of the word. See Johansson 2013 for a systematic analysis of Ingarden's 'ways of being' and 'existential moments.'

${ }^{5}$ One could say that the being of Socrates is the being of the Universe, of which Socrates is a part, as in Spinoza's pantheistic ontology. But this implies that there exists only one individual, the Universe itself. To use Russell's terminology, there is a real problem of characterizing individuality only if we adopt a pluralist ontology, not a monist one.

"Individuum vero dicitur, non quod omnino dividi not possit, sed quod ita ut singulare sit ut dividi neutiquam queat in plura particularia, in plura talia quale est ipsum, in pluri sibi similia individua.' Stephanus 
the distinction is not between independent and dependent beings, but between things that have a structural form and things that are only a piling up of other things, what we may call a conglomerate. It is, for instance, the difference between a particular rabbit and a particular pile of sand grains.

(iii) A third feature of individuality, we may label determinative singularity. Individuality relies on there being something that makes some entity different from every other thing (even if we, with our finite human minds, are unable to distinguish it in every context). If we follow Leibniz, we may even assert, a priori, that there is always a qualitative difference which explains the individuality of an entity, that which makes it this individual thing and not some other. But if we are reluctant to employ such a notion of haecceity, we must at least admit that an individual bears some determination, even external or relational, that permits its identification and re-identification. This feature also gives sense to the fact that there can be degrees of individuality: there is a lesser degree of individuality amongst a set of qualitatively identical individuals, such as industrial duplicates, than amongst a set of qualitatively distinct individuals. The ontological concept of an individual is a scalar concept, for there are grades of individuality.

Thus, a concrete entity is:

(i) ontologically separate

(ii) formally indivisible

(iii) qualitatively singular

These criteria are 'formal' in the sense that they are not specific to any material realm: any individual — an angel, an historical event, a State, as much as a living organism-will exhibit these three basic properties.

(2) The second level of analysis of the individual concept is the 'material' level of biological individuality. What is a biological individual? We find in the literature on biological individuality various criteria of biological individuality:

- reproduction or generational persistence

- genetic homogeneity

- sexual reproducibility

- bottleneck life cycle

- germa-soma separation

- functional integrity and policy mechanisms

- histocompatibility

- fitness maximisation ${ }^{\square}$

All these criteria are, at least in their formulation, peculiar to the living realm. But how do they function in relation to individuality? The defenders of the Scientific Metaphysic View might argue that they serve as possible components of a scientific re-definition of the word 'individual,' to be contrasted with the off-ground formal definition of that term. It seems to us, however, that these criteria rather serve to translate or transpose in biological terms what it is, for a living entity, to have ontological separateness (i) formal indivisibility (ii) or determinative singularity (iii). Let us briefly expound this idea.

Chauvinus $(1692,315)$.

${ }^{7}$ All these criteria are from Clarke 2010. 
(i) How do we express, in biological terms, the difference between ens per se and ens in alio? The formal concept of ens per se might be schematized or translated by contrasting entities that have a proper life and a proper cycle of life, going from birth to death, and entities that are living in another or per another, entities whose life is the life of another.

The autonomy of life criterion is difficult to apply. Yet, it seems clear that the life of a cell, say, within a multicellular organism is, to use the Husserlian vocabulary, grounded in the life of the whole to which it belongs. A cell, if we set aside the possibility of its artificial persistence in vitro, cannot have a 'proper life' (and even in vitro, there is doubt). Its life is grounded on the life of another. ${ }^{8}$

(ii) If we admit that an individual, in every realm, must be formally indivisible, that its material division would destroy its proper form or internal structure, then we should be able to express this criterion of indivisibility in biological terms.

It is here that we find criteria which focus on 'organismality,' 'functional integrity', on policy mechanisms which preserve the 'solidarity' of the parts, and on 'cohesiveness'that is, on all the criteria which aim to express the fact that a biological individual is biologically indivisible, that we lose the whole if we subtract or destroy some of its vital parts.

(iii) Finally, if an individual must have a determinative singularity, we will also have to express this idea in biological terms. We will find here criteria such as 'genetic singularity' and 'homogeneity,' 'unity of cellular origin,' 'bottleneck cycle of life,' etc.- that is, all criteria that try to express that which is constitutive of the qualitative singularity of a living thing.

Here, then, we have a 'translation' or transposition of the formal concept of an individual. If an individual is, formally speaking, a concrete entity characterized by ontological separateness or autonomy, ${ }^{\text {Q }}$ formal indivisibility and qualitative singularity, a biological individual will be a concrete living entity that is simultaneously characterized by what I will label bio-autonomy, bioindivisibility and bio-singularity, the precise meaning of these basic properties being expressed in the scientific terms outlined above.

A property of a living thing is considered as a criteria of biological individuality because these 'scientific' properties serve to schematize the formal requirement of individuality: we select these properties as constitutive of biological individuality, because we knew previously what sort of properties, amongst the various properties of a living thing, could serve as criteria or marks of individuality.

\section{(B) Mixtures and aggregates}

The problem of biological individuality arises from the attempt to transpose our 'formal' concept of an individual into diverse areas in the material realm. If we simply translate in biological terms the formal content, the resulting notion of biological individuality is problematic because the requirements of bio-autonomy, of bio-indivisibility and of bio-singularity fail to be satisfied

\footnotetext{
${ }^{8}$ It is very important to distinguish the ontological relation of grounding with the much more common phenomena of causal dependence. Any living individual depends causally on a great lot of interactions with its environment to stay alive. But it has its proper life, which is only sustained by these causal interactions. By contrast, a living part that is founded on the life of the whole to which it belongs borrows its life from the life of the whole or it lives the life of the whole.
}

${ }^{9}$ See footnote 4 . 
by the Odd Cases. It is here, then, that we have to make a choice: should we decouple the biological concept of an individual from the formal one? Or must we recognize that not all living entities are individuals, that there are non-individual living entities?

Our sympathies lie with the latter option. In order to make it more palatable, it will be helpful to flesh out an alternative category into which living entities may be place- the category of aggregates. There are numerous works in traditional metaphysics on aggregates. Here, we will briefly mention two of them.

In his correspondence with Arnauld (Leibniz 1960, letter XVI, 90-102), Leibniz contrasts the true beings that have 'real unity,' the monads, with what he labels 'aggregates.' Contrary to a monad, an aggregate is unum per accidens. However, importantly, Leibniz also recognizes that there are grades of aggregativity, as there are grades of unity (because, for instance, there is more unity in an organized human society than in a crowd, more unity in a machine than in a human organized society). An aggregate can then be more than a simple conglomerate, it may have a stability that gives it a temporal persistence. (Though, of course, ontologically speaking, an aggregate remains for Leibniz, a phenomenal being, namely a being whose unity is not 'real' but only for an observer.)

Besides Leibniz's view of aggregativity, we find another useful passage, in Aristotle's De generatione et corruptione ( 327 a30-328 b20). Therein, we encounter the two concepts of mixis and of synthesis: mixture and (as we will parse it) aggregate. Here, Aristotle is interested in determining the conceptual plausibility of 'mixtures.' The puzzle runs thus: A mixture is made of qualitatively different components, but if the components remain qualitatively distinct in the mixture, there is no mixture. And if they completely disappear, being replaced by a novel substance, there is also no mixture.

Aristotle stipulates that a mixture's components must subsist in such a way that they could be separated, that they could be extracted from the mixture. A mixture is not an irreversible transubstantiation. Further, it is essential that the components do not subsist within the mixture as qualitatively distinct components. To resolve the puzzle, Aristotle suggests that the components of a mixture do not subsist actually as qualitatively distinct components, but only in potentia. They lose their actual distinctness, but they remain potentially discernable, if they were subtracted from the mixture.

The thought that emerges is that a mixture can be divided into homogeneous parts, which are qualitatively identical with the whole. A mixture is a homeomeric entity. To highlight this property, Aristotle introduces the concept of a synthesis-which we have rendered as 'aggregate'-as a contrast. In an aggregate, contrary to a mixture, the components remain actually qualitatively distinct components. For that reason, the dissolution of an aggregate results in parts that are not qualitatively identical with the whole.

An aggregate (a synthesis) is, for Aristotle, not a real unity; it is only from the point of view of the perception (aesthesis) that an aggregate appears as a unitary entity. In itself, it is only an agglomeration of distinct components.

For present purposes, these views on aggregativity will help to characterize, in clearer terms, the concept of an aggregate:

(i) The formal concept of an aggregate is the concept of a plurality of individual concrete entities that have an external unity. An aggregate is not One thing, but Many.

(ii) However, as Aristotle and Leibniz suggest, there are grades of aggregativity. An aggregate can be a simple conglomerate of material individuals piled up on the top of each other, as in a pile of sand. 
(iii) An aggregate can also be a mixture, in which the individual parts lose their actual individuality and form a concrete homogeneous entity.

(iv) When individual living components of a biological aggregate interact with one another, their proper 'vitality $[10$ can be boosted by their aggregation. In such cases, even if the aggregation remains an external relation, it produces internal positive effects on the components (explaining why such an aggregation can be biologically beneficial to the components).

\section{Reflective Equilibria}

Let us now return to the Reflective Equilibrium Method, mentioned above, by reviewing some of the aforementioned 'Odd Cases.' As noted, we may distinguish two general puzzling cases: in one, we have a concrete whole whose parts are homogeneous. In another, we have a concrete whole whose parts are qualitatively differentiated.

Let us consider, as a representative of the first type of case, the gigantic fungus-Armillaria bulbosa-which, in the Northern Michigan Hardwood Forest, occupies a minimum of 15 hectares, weighs more than $10,000 \mathrm{~kg}$ and has remained genetically stable for more than 1,500 years (Smith et al. 1992). This odd entity satisfies both the criteria of bio-autonomy and bio-singularity, but it does not satisfy the requirement of bio-indivisibility (for that unitary entity could be really or physically divided in shorter parts, salva vitalitate). Is $A$. bulbosa One thing or Many? We have to make a choice between two possibilities: We might revise our concept of an individual or we might increase categorial complexity. Contrary to a heteronomous (differentiated) organism, the fungus can be divided in such a way that the products of the division are individuals of the same kind as the whole from which they proceed. Thus, $A$. bulbosa might lead us to introduce the concept of something like an accidental individual, a genuine individual that could however be many individuals if it was physically divided. This would be a case of revising our formal concept of an individual by introducing a difference between essential and accidental individuals. Alternatively, we might opt to increase categorial complexity. Because $A$. bulbosa is not indivisible, because its real physical nature is constituted by a web of intertwined hyphae which count as clonal indivisible individuals, it is a mixture of individuals, therefore not itself One individual but Many, whose proper lives are however boosted by their physical aggregation.

The second class of puzzle cases - the class of the concrete entities made of differentiated individualized parts-comprises at least two different sub-cases. (i) Cases emerging from the pervasive phenomenon of symbiosis, where a dominant individual is biologically associated with other hosted individuals. (ii) The fascinating class of siphonophores, where a concrete living entity, develops as many individual entities collaborating with one another. In both cases, the requirement of bio-indivisibility is satisfied, but there is some hesitation for the requirements of bio-autonomy and of bio-singularity because of the presence of a plurality of individuals.

Let us first consider the symbiosis cases. We must again make the choice between revising our concept of an individual and increasing categorial complexity. Because a host-symbiont association is made of genetically different individuals, which preserve their individual nature during symbiosis, it is difficult to treat a concrete singular host-symbiont association as a genuine individual. However, because of the reciprocal vital dependence between the dominant individual and its endosymbionts, we can be tempted to assimilate the vital interdependence of the individuals to the vital interdependence of organs within a genuine organism. We could then decide to introduce the concept of a super-individual to capture that analogy with the internal structure of an organism, all the while taking into account the differentiated biological nature

${ }^{10}$ 'Vitality' can here be understood as temporal longevity and aptitude to reproduction. 
of the associates. A super-individual might satisfy the requirement of bio-autonomy and of bio-indivisibility, but not of bio-singularity, for it is composed of a plurality of genetically differentiated individuals. A super-individual would then be an individual that is made of actually distinct individuals.

Alternatively, again we might opt for an increase in categorial complexity. The phenomena of symbiosis can also be viewed as a boosting aggregation, which implies that the associated individuals are not simply piled up, as is the case in a conglomerate (cf. 3 (B) supra), but that they are internally and beneficially supported and boosted, thanks to the correspondence of their own biological activities. We could then view a host-symbiont association as a biologically stabilized aggregate, unable to reproduce itself (a host-symbiont association is not (or at least, not uncontroversially) an unity of reproduction), but able to function as a real biological attractor of differentiated individuals.

When we turn to siphonophores, 11 the hesitation between the One and the Many is much more critical than in the case of symbionts. Not only do we have an entity that satisfies the requisite of bio-indivisibility, it also satisfies the requirement of bio-singularity. A siphonophore develops from a fertilized egg that first becomes a singular zooid which, through a form of budding, in turn gives birth to other differentiated zooids. Each zooid in the siphonophore is of a sort that has solitary exemplars elsewhere in nature, but when they are situated within a siphonophore, they become specialized like an organ in an organism.

The choice here is more complex. We can choose between (i) Genuine individuality-if we consider that, towards the requirements of bio-indivisibility and bio-singularity, the requirement of bio-autonomy is satisfied by the fact that the whole has a unique cycle of life, a unity of birth and of death. (ii) Super-individuality - if we consider that each zooid is genetically identical with the others but, specifically, of a different sort or variety than the others and that some of the conspecifics of each zooid actually may exist apart in nature (polyps). (iii) Stabilized aggregativity - if we consider that each zooid has, strictly speaking, its own cycle of living and process of behaving, all these cycles and processes being simply synchronized with one another.

\section{Adjudications}

How can we adjudicate between these various possibilities? Why would one prefer a revision of our core individual concept (admitting 'accidental' individuals and 'super-individuals') to an increase in categorial complexity (admitting, in the living realm, mixtures and stabilized aggregates beside organic individuals?). The adjudication cannot be a matter of taste or pragmatic convenience: if metaphysics aims at true knowledge, if it aims to tell us what there really is, the choice between revisionary individuality and stabilized aggregativity must include an answer to a much more fundamental question, which concerns what we may call the 'predominant ontological orientation of the historical life process.'

Two opposite answers can, in principle, be given to this question. Firstly, we can adopt an Individuals-Oriented View of the historical development of life. According to this view, the development of living forms has to be seen as a process of individuals building; each new living form, stabilized by natural selection, is necessarily a new kind of individual, made up of previous simpler individuals. Here, there is a kind of analytical link between life and individuality: individuality is a necessary condition of the stability in duration and in reproduction of a life form.

\footnotetext{
${ }^{11}$ Materials below come from http://www.siphonophores.org/SiphOrganization.php.
} 
Yet the Individuals-Oriented View is not the only acceptable conception of the ontological orientation of life historical process. An alternate view is the Aggregates-Oriented View of the development of life. According to this view, the historical development of living forms, through natural selection, could be seen as a process of aggregation of simpler living entities, a process that can contain-locally, but not universally - processes of individualization or of superindividualization. According to this conception, the default-setting of the life building process would be aggregation, the stabilization of an aggregate being the verdict of natural selection mechanisms. Individualization would then only be a supplementary grade of aggregation, a kind of fusion of the Many into the One, that would occur only when it would give a selective advantage to the One over the (stabilized) Many.

It seems to us that neither of these extreme views is true, but, also, that neither is false! The question of the predominant ontological orientation of the life historical process is not a purely speculative one. This question can find a mid-theoretical, mid-empirical treatment though the identification and the explanation of what Maynard Smith and Szathmary (1995) called the major transitions in evolution. In a recent synthetic paper, to the richness of which we cannot do due justice, West et al. (2015) ${ }^{12}$ have proposed a general model of what they call 'major evolutionary transitions in individuality.' Such a formulation seems to imply that the authors adopt the Individuals-Oriented View of life historical process. The details of their model, however, suggest a more nuanced position. According to their analysis "in each transition, a group of individuals that could previously replicate independently cooperate to form a new, more complex life form" (Ibid., 10112). More precisely:

a major evolutionary transition is defined by two conditions. First, entities that were capable of independent replication before the transition can replicate only as part of a larger unit after it, termed mutual dependence, interdependence or contingent irreversibility. Second, there is a relative lack of within-group conflict such that the larger unit can be thought of as a fitness-maximizing individual (or organism) in its own right. [...] When these two conditions are met, evolution can lead to a new higher level individual (organism). We have a group that can't be broken up (condition 1) and we can conceptualize the group with a single purpose, where the interests of the previously independent individuals are now aligned (condition 2). (Ibid.)

For our purpose, the main point here is that the emergence of new kinds of individuals, made from simpler cooperating individuals, is, of course, not a teleological process. Some logically necessary but empirically contingent conditions are required for the emergence of the One out of the Many and it can be the case that these conditions aren't met. 'For example, clonal multicellular groups have led to animals and plants whereas nonclonal multicellular groups have led to things like slime moulds' (Ibid., 101117).

This means that even if major evolutionary transitions are transitions towards individuality and if it is the achievement of individuality that makes them major transitions, the fundamental process from which individuals emerge can also lead to non-individualized cooperative aggregates, because some necessary conditions of individuality are lacking: the components can continue to reproduce independently or the whole can be broken up, salva vitalitate. But the stability of these non-individualized aggregates suggests that life evolution can also be content, at least marginally, with reversible biological cooperation.

\footnotetext{
${ }^{12}$ Thanks to Thomas Pradeu for this reference.
} 
So even if individualization appears as a critical step in evolution, individualization supervenes on a more basic aggregation trend: one that may sometimes fall short of an individualized form.

\section{Conclusion}

In this paper we have contrasted the Scientific Metaphysics View of the problem of biological individuality with the Reflective Equilibrium View of that problem. It appears now more clearly that behind these two divergent methodologies, there is a deeper divide between two different views of what we may call the ontological orientation of the evolution of life. The methodological parti pris of the 'Scientific Metaphysics View' is in fact the methodological consequence of the general assertion that every living concrete entity, stabilized by natural selection, must count as an individual. It is because of this assertion concerning the ontological orientation of life that the scientific metaphysician is committed to accept that individual-hood is much more complicated, much more diversified than what our common concept of an individual allows.

But such an Individuals-Oriented View of the evolution of life forms must be tempered by what we can now called an 'Aggregates-Deviation' View of the evolution of life forms. Even if stabilized aggregates are not always major life forms, they are real living entities. The problem of biological individuality is then as much an invitation to critically revise or refine our common concept of an individual than to pay attention to the categorical richness of the concrete nonindividuals.

The lesson we can glean from the problem of biological individuality is that an individualoriented ontology must go hand in hand with an ontology of aggregativity.

\section{Literature cited}

Aristotle. 1982. On Generation and Corruption. Translated by C. J. F. Williams. Oxford: Clarendon Press.

Chauvier, Stéphane. 2016. "Why Individuality Matters.” In Individuals Across Sciences, edited by Alexander Gay and Thomas Pradeu, 25-45. New York: Oxford University Press.

Chauvinus, Stephanus. 1692. Lexicon Rationale Sive Thesaurus Philosophicus. Rotterdam: Petrus van der Slaart.

Clarke, Ellen. 2010. "The Problem of Biological Individuality." Biological Theory 5 (4): 1-15.

Hull, David. 1978. "A Matter of Individuality.” Philosophy of Science 45 (3): 335-360.

Husserl, Edmund. 1970. Logical Investigations. Translated by J. N. Findlay. London: Routledge \& Kegan Paul.

Ingarden, Roman. 2013. Controversy over the Existence of the World. Translated by A. Szylewicz. Frankfurt am Main: Peter Lang.

Johansson, I. 2013. “The Basic Distinctions in Der Streit.” Semiotica 194: 137-157.

Ladyman, J., and D. Ross. 2007. Everything Must Go: Metaphysics Naturalized. Oxford: Oxford University Press.

Leibniz, G. W. (1879) 1960. Die philosophischen Schriften von Gottfried Wilhelm Leibniz. Vol. 2. Edited by Carl Immanuel Gerhardt. Reprint edition. Hildesheim: Georg Olms.

Maynard Smith, J., and E. Szathmary. 1995. The Major Transitions in Evolution. Oxford: Oxford University Press. 
Rawls, John. 1999. A Theory of Justice. Revised Edition. Cambridge, MA: Harvard University Press.

Smith, M. L., et al. 1992. “The Fungus Armillaria Bulbosa Is Amongst the Largest and Oldest Living Organisms." Nature 356 (2): 428-431.

Strawson, P. F. 1959. Individuals: An Essay in Descriptive Metaphysics. London: Routledge.

West, S. A., R. M. Fisher, A. Gardner, and T. Kiers. 2015. "Major Evolutionary Transitions in Individuality." Proceedings of the National Academy of Sciences 112 (33): 10112-10119.

(C) 2017 Author(s)

This is an open-access article distributed under the terms of the Creative Commons AttributionNonCommercial-NoDerivatives 4.0 International license, which permits anyone to download, copy, distribute, or display the full text without asking for permission, provided that the creator(s) are given full credit, no derivative works are created, and the work is not used for commercial purposes.

ISSN 2475-3025 